\title{
Assessment of Structural Differences between Water-Extracted and Non-Extracted Hydro-Thermally Treated Spruce Wood by NIR Spectroscopy
}

\author{
Carmen-Mihaela Popescu 1,2,*DD, Nanami Zeniya ${ }^{1}$, Kaoru Endo ${ }^{1}$, Takuma Genkawa ${ }^{1}$ (D), Miyuki Matsuo-Ueda ${ }^{3}$ \\ and Eiichi Obataya ${ }^{1}$ \\ 1 Graduate School of Life and Environment Sciences, University of Tsukuba, Tsukuba 305-8577, Japan; \\ zeniya.773@gmail.com (N.Z.); kaoru.end.0123@gmail.com (K.E.); \\ genkawa.takuma.fm@alumni.tsukuba.ac.jp (T.G.); obataya.eiichi.fu@u.tsukuba.ac.jp (E.O.) \\ 2 Petru Poni Institute of Macromolecular Chemistry of the Romanian Academy, 700487 Iasi, Romania \\ 3 Graduate School of Bioagricultural Sciences, Nagoya University, Nagoya 464-8601, Japan; \\ miyuki@agr.nagoya-u.ac.jp \\ * Correspondence: mihapop@icmpp.ro
}

\section{check for} updates

Citation: Popescu, C.-M.; Zeniya, N.; Endo, K.; Genkawa, T.; Matsuo-Ueda, M.; Obataya, E. Assessment of Structural Differences between Water-Extracted and Non-Extracted Hydro-Thermally Treated Spruce Wood by NIR Spectroscopy. Forests 2021, 12, 1689. https://doi.org/ $10.3390 /$ f12121689

Academic Editor:

Antonios Papadopoulos

Received: 1 November 2021

Accepted: 29 November 2021

Published: 2 December 2021

Publisher's Note: MDPI stays neutral with regard to jurisdictional claims in published maps and institutional affiliations.

Copyright: (c) 2021 by the authors. Licensee MDPI, Basel, Switzerland. This article is an open access article distributed under the terms and conditions of the Creative Commons Attribution (CC BY) license (https:/ / creativecommons.org/licenses/by/ $4.0 /)$.

\begin{abstract}
Sitka spruce wood samples were subjected to different conditions of hydro-thermal treatment by varying the relative humidity $(\mathrm{RH})$ and period of exposure at a constant temperature of $120{ }^{\circ} \mathrm{C}$. Near infrared (NIR) spectroscopy, principal component analysis (PCA) and two dimensional correlation spectroscopy (2D-COS) were employed to examine the structural changes which occur in the wood samples during the applied treatment conditions and to quantify the differences between non-extracted and water-extracted wood specimens after the treatment. Modifications were dependent on the amount of water molecules present the medium and also on treatment time. Higher variations were observed for samples treated at higher RH values and for longer periods. At the same time, it was also observed that during the hydro-thermal treatment a high amount of extractives remain in the wood structure, extractives which vary in quantity and composition. PCA and 2D-COS made it possible to discriminate modifications in the wood samples according to treatment time and relative humidity. Non-extracted and water-extracted samples were also examined to identify the sequential order of band modification.
\end{abstract}

Keywords: Sitka spruce; hydro-thermal treatment; water soluble extractives; near infrared spectroscopy; principal component analysis; 2D-COS

\section{Introduction}

Wood, a natural composite material, is used in many applications, but due to its structural features and depending on the environmental conditions (humidity, temperature and biological agents), it can be easily degraded. Three major components (cellulose, lignin and hemicelluloses) along with low molecular compounds are the major components of wood [1-3]. In order to understand wood degradation mechanisms taking place under natural environmental conditions (during material service life), many researchers have simulated accelerated ageing by using biodegradation factors, such as soft, brown and white rot fungi or termites [4-6]; thermal and hydro-thermal ageing [7-9] or weathering and UV light exposure $[10,11]$.

Thermal and hydro-thermal treatments are often used to improve the dimensional stability, durability and hydrophobicity of wood [12-14], but at the same time they can be used as an accelerated technique to simulate the natural ageing of wood [7-9,15-17]. In order to simulate, as close as possible, natural ageing conditions, a certain amount of water should be added in the degradation medium, because natural ageing takes place at moderate relative humidity. However most studies were conducted in thermal dry 
conditions or in 100\% RH atmosphere. Few studies investigate the intermediate values of RH during heating [7-9,17-22].

To investigate modifications taking place in wood during different treatments, spectral techniques, particularly near infrared spectroscopy (NIRS), are used, owing to a combination analysis speed, little or no sample preparation, ease of use, non-destructiveness, good reproducibility and low cost instrumentation [21,23]. Small changes in the chemical composition or physico-chemical properties of materials will cause spectral changes in diffusely reflected NIR radiation, with multiple chemical absorptions considerably affecting the shape of the near infrared spectra giving shifts in position of maxima, band intensity changes and baseline offset $[6,7,23]$. For wood, NIRS can be successfully used for the non-destructive evaluation of stiffness (i.e., [24]) and structural changes during thermal treatment $[7,21,25]$.

Principal component analysis (PCA) is a well-established chemometric technique. By converting the data into the dimensionally reduced PCA space, the input data set is decomposed into two matrices of interest: scores and loadings [26,27]. The loadings matrix defines the new axes of the dimensionally reduced data set, while the scores matrix describes the samples in the PC space. With PCA, the most important features of the NIR spectra of examined samples can be identified, and band shifts and non-symmetries in bands amongst the samples can be quickly determined [7,21,26].

Two dimensional correlation spectroscopy (2D-COS), a technique established by Noda in 1993 [28], is based on the computation of auto-correlation and cross-correlation between spectra and provides a graphical overview for the analysis of external perturbation induced variations. This external perturbation can be related to temperature, pressure, moisture, concentration, composition, $\mathrm{pH}$ or time change [28-30]. 2D correlation analysis can be applied to various types of systems, once the external perturbation is described as a specific function. The method was applied in wood science to both mid (i.e., $[6,10,31])$ and near infrared spectroscopy $[7,21,32]$. 2D-COS provides two different correlation maps: a synchronous map which displays correlations between the spectral bands changing in phase and indicate whether they increase or decrease relative to each other; and an asynchronous map, which relates to spectral bands that change at different rates and contains information about the sequence of the occurring events.

In previous papers [8,9], the time-temperature-superposition relationship for prediction of mass loss of wood after hydro-thermal treatment at arbitrary temperature and relative humidity, as well as the mass loss dependencies of vibrational properties and color parameters, were discussed. In this study, we intend to evaluate the relationship between the applied treatment and the related structural changes taking place, and to assess the differences between non-extracted and water-extracted samples after treatment by using NIRS, PCA and 2D-COS.

\section{Materials and Methods}

\subsection{Materials}

Sitka spruce (Picea sitchensis) wood samples cut from the same lumber (which was selected for use as harp soundboard) having an average density of $439 \mathrm{~kg} / \mathrm{m}^{3}$ and dimensions $15 \mathrm{~mm}$ (radial) $\times 1.6 \mathrm{~mm}$ (tangential) $\times 120 \mathrm{~mm}$ (longitudinal) were used. The hygroscopic history during seasoning was removed by moistening the wood samples for 5 days at $100 \% \mathrm{RH}$ and $25^{\circ} \mathrm{C}$, and then vacuum drying on phosphorus pentoxide for 7 days at the same temperature.

For the hydrothermal treatment a closed system was used. The samples previously conditioned for 30 days at different values of $\mathrm{RH}(0,35,60,80$ or $91 \% \mathrm{RH})$ and $25^{\circ} \mathrm{C}$, were placed in an autoclave with different amounts of deionized water to achieve specified RH values (in the medium), then sealed and heated up to $120^{\circ} \mathrm{C}$. The system was equipped with thermocouple and pressure sensor (PHS-B-500KP, Kyowa Electronic Instruments Co., Tokyo, Japan). Details about the system and the calculation of the parameters are given in 
a previous paper [17]. For the treatment at $0 \% \mathrm{RH}$ an air-circulating oven was used. The samples were treated for 1, 2, 4 and 7 days in five replicates.

After treatment all samples were removed from the autoclave, cooled at room temperature and vacuum dried on $\mathrm{P}_{2} \mathrm{O}_{5}$ to determine absolute dry mass.

To remove the decomposition products trapped in the wood, all samples were cut in half. One was kept for further analysis, while the other was soaked in the water at room temperature $\left(20-25^{\circ} \mathrm{C}\right)$ for a period of 8 days with the water replaced every day. After this period, the samples were again vacuum-dried on $\mathrm{P}_{2} \mathrm{O}_{5}$ for one week in order to determine again the absolute dry mass.

The two series of samples (non-extracted and extracted) were further analyzed.

\subsection{Methods}

Near Infrared spectra were recorded in the diffuse reflection mode for non-extracted and water-extracted control and hydro-thermal-treated wood samples on a NIRFlex-N500 instrument (BÜCHI Labortechnik AG, Flawil, Switzerland), in the $4000-10,000 \mathrm{~cm}^{-1}$ spectral range with $4 \mathrm{~cm}^{-1}$ intervals. Each sample was represented by five specimens.

In order to identify the differences which may appear after the hydro-thermal treatment and water extraction, the treated samples were compared with the non-treated ones, used as the control. The data processing and chemometric methods were performed using The Unscrambler ${ }^{\circledR}$ X 10.4.1 program (CAMO AS, Trondheim, Norway), and the generalized 2D correction spectra were processed in a Matlab program (developed by Maria-Cristina Popescu). For the NIR spectra and their second derivatives, as well as to draw the PC scores and 2D-COS maps only the medium spectrum obtained from the five components spectra was used. Second derivative spectra were obtained using Savitzky-Golay method with 21-points smoothing. For PCA, the second derivative spectra in the $4520-7104 \mathrm{~cm}^{-1}$ region were used. 2D-COS was employed to highlight the differences between the nonextracted and water-extracted specimens and to identify the sequential order of chemical modifications.

\section{Results and Discussion}

NIR spectroscopy is a useful and sensitive tool for highlighting the small modifications taking place in the wood structure during these treatments. The modifications induced by the hydro-thermal treatments in the structure and content of non-extracted and waterextracted Sitka spruce wood are reflected in the NIR bands intensities, maxima and width.

\subsection{NIR Spectroscopy}

NIR spectra for all samples (control/ untreated, hydro-thermally treated and hydrothermally treated and water-extracted) were recorded on dried specimens. Independent of the applied treatment, the spectra (not shown) showed similar shapes with typical broad absorption bands. Small variations in band intensities and width, as well as shifting of their maxima were observed. In contrast to mid-infrared spectroscopy, in NIRS it is more difficult to assign bands to specific functional groups because broad spectral features are comprised of several overlapping signals. Moreover, the reason of increase or decrease a certain band intensity may be due to only one component band intensity modification or shifting of its position. Therefore, it is sensible to use the second derivative in order to examine the individual bands, and to detect the variations between the samples.

Figure 1 highlights second derivative spectra in two regions $\left(4520-5350 \mathrm{~cm}^{-1}\right.$-left side graphs and $5600-6950 \mathrm{~cm}^{-1}$ —right side graphs), where higher differences between the sample sets were observed. 


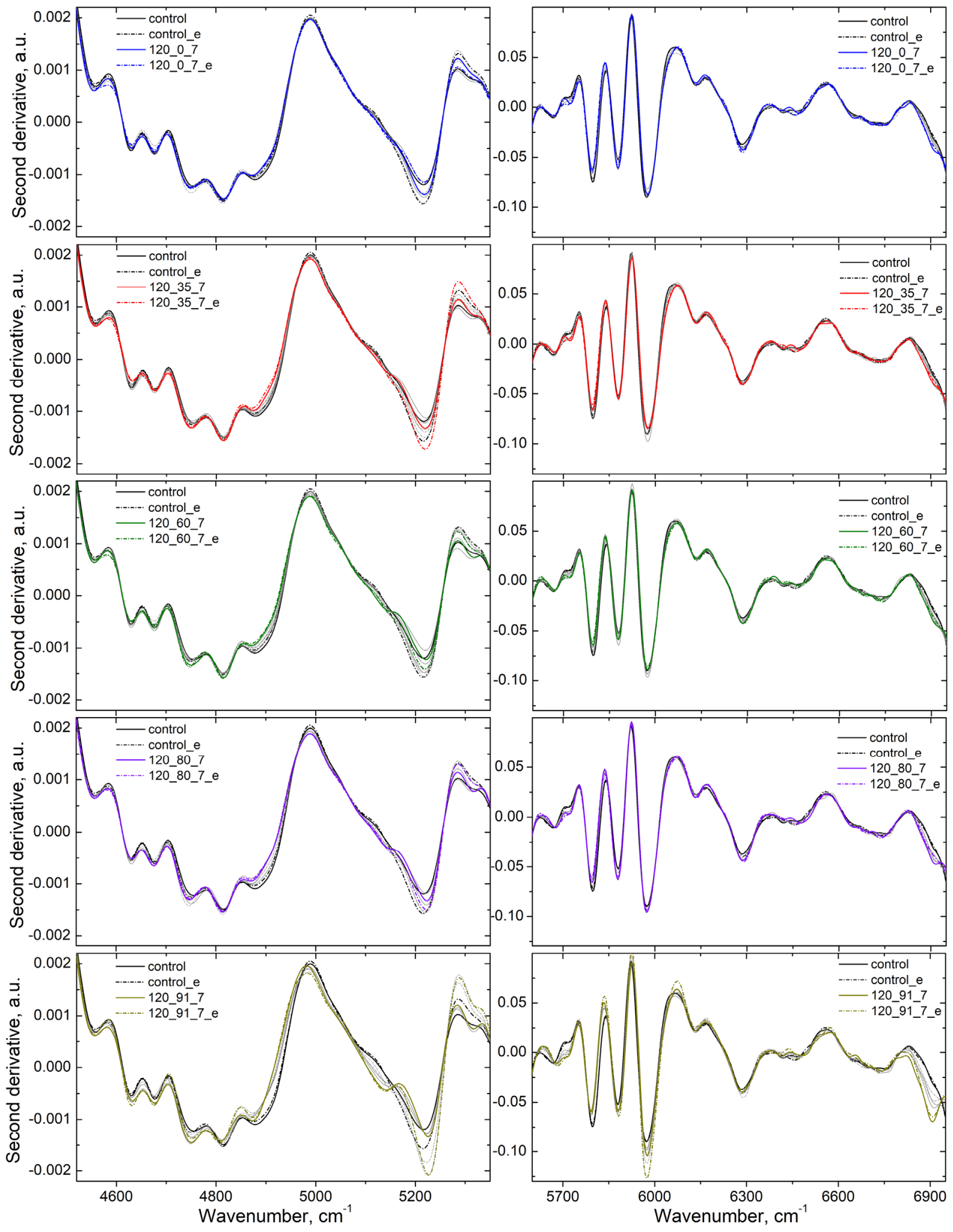

Figure 1. Second derivative of the NIR spectra in the 4520-5350 and 5600-6950 $\mathrm{cm}^{-1}$ regions for control (black full line colour), hydro-thermal treated (coloured full line contours) and water-extracted (dotted line contours) spruce wood samples $\left(\mathrm{T}=120^{\circ} \mathrm{C} ; \mathrm{RH}=0,35,60,80,91 \%\right.$; treatment time $=7$ days; e-extracted $)$. The spectral lines of the control and samples after the thermal treatment were highlighted, while the spectra of the samples with intermediary treatment time are represented with thinner grey lines. We kept the same colours for the extracted and non-extracted samples. 
In the first region (4520-5350 $\mathrm{cm}^{-1}$ ) several bands were identified at 4559, 4632, 4676, $4756,4816,4878,5092,5140,5216$ and $5312 \mathrm{~cm}^{-1}$ and their assignments are presented in Table 1.

Table 1. Band position and their assignment in the $4520-5350 \mathrm{~cm}^{-1}$ region $[7,23]$.

\begin{tabular}{|c|c|}
\hline Band Position & Assignment \\
\hline 4559 & combination band of $\mathrm{C}-\mathrm{H}$ and $\mathrm{C}=\mathrm{O}$ stretching vibration associated to lignin \\
\hline 4632 & combination bands of $\mathrm{Car}-\mathrm{H}$ and $\mathrm{C}=\mathrm{O}$ stretching vibration associated to lignin and extractives \\
\hline 4676 & $\mathrm{C}-\mathrm{H}$ and $\mathrm{C}=\mathrm{O}$ stretching vibration associated to hemicelluloses \\
\hline 4756 & $\mathrm{O}-\mathrm{H}$ and $\mathrm{C}-\mathrm{H}$ deformation and $\mathrm{O}-\mathrm{H}$ stretching vibrations in cellulose and hemicelluloses \\
\hline 4816 & $\mathrm{O}-\mathrm{H}$ and $\mathrm{C}-\mathrm{H}$ deformation vibrations in cellulose and hemicelluloses \\
\hline 4878 & $\mathrm{C}=\mathrm{O}$ stretching vibration associated to hemicelluloses \\
\hline 5092 & combination bands of $\mathrm{O}-\mathrm{H}$ and $\mathrm{C}-\mathrm{H}$ stretching vibration \\
\hline 5140 & \multirow{3}{*}{$\begin{array}{c}\text { O-H groups involved in strong intramolecular hydrogen bonds and 2nd overtone of } \mathrm{C}=\mathrm{O} \text { stretching } \\
\text { vibration mainly in hemicelluloses }\end{array}$} \\
\hline 5216 & \\
\hline 5315 & \\
\hline
\end{tabular}

The bands from 5140, 5216 and $5312 \mathrm{~cm}^{-1}$ are generally overlapped with the band from water with a maximum at $5155 \mathrm{~cm}^{-1}$ [33], but in this case, the spectra of the dried specimens were recorded. Hence, there is little or no influence of water in the spectra. Therefore, these bands may be assigned to $\mathrm{O}-\mathrm{H}$ groups involved in strong intramolecular hydrogen bonds [34], as well as to a 2 nd overtone of $\mathrm{C}=\mathrm{O}$ stretching vibration [23].

Two separate types of differences can be identified in the second derivative spectra of the studied samples: (I) the modifications induced by the hydro-thermal treatment (full line contours), and (II) the modifications induced by the water extraction process (dotted line contours).

During the treatment, the bands from 4630 and $4676 \mathrm{~cm}^{-1}$ slightly decrease for the treated samples at 0 and $35 \% \mathrm{RH}$, are almost constant for the hydro-thermal treated samples at $60 \% \mathrm{RH}$ and increase for those treated at 80 and $91 \% \mathrm{RH}$, compared to the control. These variations are induced by the elimination and further formation of new compounds, mostly from hemicelluloses during the treatment [7], but also may be due to condensation reactions or some conformational and molecular rearrangements in lignin (lignin undergo glass transition around the temperature used for treatment, transitions which can be accelerated due to the presence of water molecules) $[7,35,36]$. The bands at 4756 and $4816 \mathrm{~cm}^{-1}$ are shifted to lower wavenumber, with $4756 \mathrm{~cm}^{-1}$ presenting a slight intensity increase, while for $4816 \mathrm{~cm}^{-1}$, intensity and width decreased. Bands at 5140, 5216 and $5312 \mathrm{~cm}^{-1}$ slightly increase in intensity with an increase of treatment time. These modifications are stronger when the moisture content in the samples increases during the treatment (i.e., 80 and 91\% $\mathrm{RH}$ in the treatment environment).

Comparing non-extracted (full line contour) and water-extracted (dotted line contour) wood samples, a further decrease and shifting to lower wavenumber of bands from 4756 and $4816 \mathrm{~cm}^{-1}$, increase and shifting to lower wavenumber of the band from $5212 \mathrm{~cm}^{-1}$ and decrease/disappearance of the band from $5312 \mathrm{~cm}^{-1}$ is observed. The modification induced for these bands indicate that the non-volatile low molecular carbonyl or carboxyl compounds formed during treatment and trapped in the wood structure are leaching out in cold (room temperature) water. The band from $5212 \mathrm{~cm}^{-1}$ assigned to stronger intermolecular hydrogen bonds may reveal the formation of new hydrogen bonds after the removal of low molecular compounds from the wood structure.

In the second region $\left(5600-6950 \mathrm{~cm}^{-1}\right)$, the second derivative spectra reveal bands at: $5667,5720,5796,5880,5972,6136,6283,6418,6464,6647,6708,6753$ and $6908 \mathrm{~cm}^{-1}$. Band assignments are presented in Table 2. 
Table 2. Band position and their assignment in the $5600-6950 \mathrm{~cm}^{-1}$ region $[7,23,37-39]$.

\begin{tabular}{|c|c|}
\hline Band Position & Assignment \\
\hline 5667 & 1st overtone of C-H stretching vibration in carbohydrates and lignin \\
\hline 5720 & 1st overtone of C-H groups in hemicelluloses \\
\hline 5796 & 1st overtone of C-H stretching in lignin \\
\hline 5880 & 1st overtone of $\mathrm{C}-\mathrm{H}$ stretching in lignin and $\mathrm{CH}_{2}$ groups in cellulose \\
\hline 5972 & $\mathrm{C}_{\mathrm{ar}}-\mathrm{H}$ stretching vibration in lignin \\
\hline 6136 & 1st overtone of $\mathrm{O}-\mathrm{H}$ stretching vibration in cellulose \\
\hline 6283 & $\begin{array}{l}\text { 1st overtone of } \mathrm{O}-\mathrm{H} \text { stretching vibration in cellulose, strongly bonded } \mathrm{O}-\mathrm{H} \text { groups in crystalline regions } \\
\text { and } \mathrm{I} \beta \text { phase }\end{array}$ \\
\hline 6418 & 1st overtone of $\mathrm{O}-\mathrm{H}$ stretching vibration of the $\mathrm{O}(6)-\mathrm{H}(6) \ldots \mathrm{O}(3)^{\prime}$ intermolecular $\mathrm{H}$-bonds in cellulose \\
\hline 6464 & $\begin{array}{c}\text { 1st overtone of } \mathrm{O}-\mathrm{H} \text { stretching vibration of the } \mathrm{O}(3)-\mathrm{H}(3) \ldots \mathrm{O}(5) \text { intramolecular H-bonds in cellulose } \\
\text { (crystalline regions } \mathrm{C} 1 \text { ) }\end{array}$ \\
\hline 6647 & 1st overtone of $\mathrm{O}-\mathrm{H}$ stretching vibration of the $\mathrm{O}(6)-\mathrm{H}(6) \ldots \mathrm{O}(3)^{\prime}$ intermolecular $\mathrm{H}$-bonds in cellulose \\
\hline 6708 & $\begin{array}{c}\text { 1st overtone of } \mathrm{O}-\mathrm{H} \text { stretching vibration of the } \mathrm{O}(3)-\mathrm{H}(3) \ldots \mathrm{O}(5) \text { intramolecular } \mathrm{H} \text {-bonds in cellulose and } \\
\text { glucomannan }\end{array}$ \\
\hline 6753 & $\begin{array}{l}\text { weakly hydrogen bonded } \mathrm{OH} \text { groups of cellulose } \mathrm{O}(6)-\mathrm{H}(6), 1 \text { st overtone of } \mathrm{O}-\mathrm{H} \text { stretching vibration in } \\
\text { semi-crystalline cellulose }\end{array}$ \\
\hline 6908 & $\begin{array}{c}\text { phenolic O-H groups of lignin with intramolecular H-bonding to an ether group in ortho position and to } \\
\text { extractives }\end{array}$ \\
\hline 5667 & 1st overtone of $\mathrm{C}-\mathrm{H}$ stretching vibration in carbohydrates and lignin \\
\hline 5720 & 1st overtone of C-H groups in hemicelluloses \\
\hline
\end{tabular}

After treatment, the band from $5667 \mathrm{~cm}^{-1}$ is shifted to $5680 \mathrm{~cm}^{-1}$ in the spectrum of the sample treated at $91 \% \mathrm{RH}$, while the band from $5720 \mathrm{~cm}^{-1}$ increases in intensity with increasing time and $\mathrm{RH}$ values and is shifted to lower wavenumber, almost merging with the previous band at the higher relative humidity values. The other three bands (5796, 5880 and $5972 \mathrm{~cm}^{-1}$ ) present almost no modification for the samples treated at $\mathrm{RH}$ values of 0 and $35 \%$, but modify at higher $\mathrm{RH}$ values. The first band $\left(5796 \mathrm{~cm}^{-1}\right)$ decreases and is shifted to lower wavenumber, while the other two bands (5880 and $5972 \mathrm{~cm}^{-1}$ ) increase in intensity with the increasing time and $\mathrm{RH}$ values. The reduction of the first band might be due to the degradation of hemicelluloses and/or their deacetylation, while the increase in intensity of the other two bands might be due to the relative increase and structural variation of lignin (demethoxylation and condensation reactions may occur in lignin structure during the thermal and hydro-thermal treatment). Similar behaviours have been reported by Bächle et al. [40] (for a higher temperature treatment), and by Popescu et al. [7], which used $130{ }^{\circ} \mathrm{C}$ and up to $25 \% \mathrm{RH}$.

The bands from 6647,6708 and $6753 \mathrm{~cm}^{-1}$ decrease in intensity and shift to lower wavenumber, indicating modifications in the hydrogen-bonded $\mathrm{OH}$ groups. The band from $6908 \mathrm{~cm}^{-1}$ increases in intensity with the increase of the treatment time and $\mathrm{RH}$ values. The modifications in this region are due mostly to hemicelluloses degradation, but also amorphous cellulose or lignin can be affected, with the formation of new extractive compounds, which affect absorption bands in this region.

Comparing NIR spectra from non-extracted (full line contour) and water-extracted (dotted line contour) specimens, bands from 5796, 5880, 6647 and $6908 \mathrm{~cm}^{-1}$ decrease in intensity, while bands from 6708 and $6753 \mathrm{~cm}^{-1}$ are shifted towards each other and present a slight intensity decrease. The decrease in intensity of these bands is due to a decrease in the amount of $\mathrm{CH}$ groups as well as $\mathrm{OH}$ groups, which are involved in intermolecular hydrogen bond interactions. These observations indicate further the elimination of the non-volatile low molecular weight compounds containing $\mathrm{OH}$ groups in their structures 
and which were formed during hydro-thermal treatment and remain trapped in the wood structure.

The wet chemical analysis of extractives [22] indicated an increase in the water soluble low molecular weight compounds with an increase in water content in the autoclave during treatment (up to almost 16\% for the treated samples at the highest RH level and for the longest period). At the same time, the content of monomeric and oligomeric structures varied among the applied treatment. The wood treated at values of RH lower than $75 \%$ presented oligomers as the major fraction in the water-extracted substances, while the samples treated at higher values presented large amounts of monomeric structures.

\subsection{Principal Component Analysis (PCA)}

PCA was used to compare the non-extracted and water-extracted spruce wood NIR spectra. Variations were identified by the first two principal components (PC1 and PC2) with $58 \%$ of the total variance in the spectra explained by PC1 and 29\% explained by PC2. Therefore, the score and loading plots of the first two principal components can be used to explain the differences/similarities of constituents in terms of chemical structure.

The PC scores and loadings are presented in Figure 2. Because it would have been difficult to follow the colours and position of plots, it has been decided to use only the medium spectrum obtained from all the spectra with similar samples characteristics.

PC1 and PC2 scores are plotted in Figure 2a.

The PC1 explains all the spectral modification taking place due to applied treatment, while the PC2 can be attributed to the spectral differences as a function of the extraction process.

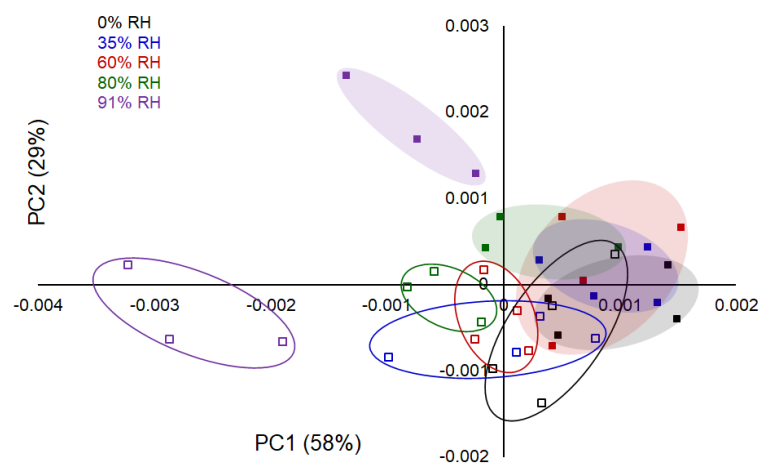

(a)

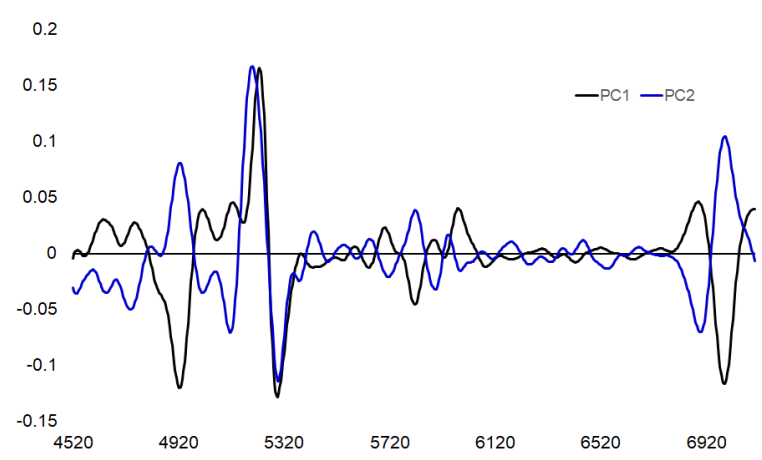

(b)

Figure 2. PC scores (a) in the $4520-6950 \mathrm{~cm}^{-1}$ region for non-extracted and water-extracted spruce wood specimens (full symbols-non-extracted specimens; open symbols—-water-extracted specimens; colours represent the different levels of RH during heating) and loadings (b) in the same region.

Figure $2 \mathrm{~b}$ presents the chemical features (loading plots) which differentiate the treated specimens, as well as non-extracted and water-extracted ones. PC1 loadings show several negative $\left(5296,5820\right.$ and $\left.6988 \mathrm{~cm}^{-1}\right)$ and positive $\left(4644,4764,5132,5208,5712,5988 \mathrm{~cm}^{-1}\right)$ bands. The negative signals appear to be shifts of the bands from 5312 and $5796 \mathrm{~cm}^{-1}$ assigned to weakly hydrogen-bonded $\mathrm{OH}$ groups in amorphous carbohydrates and $\mathrm{CH}$ groups in extractives $[7,23,37]$, while the positive ones are shifts of the bands from 4632, $4756,5140,5216,5720,5972$ and $6908 \mathrm{~cm}^{-1}$ assigned to $\mathrm{CH}$ groups in extractives and lignin as well as $\mathrm{OH}$ groups in extractives and amorphous carbohydrates $[7,23,37]$.

PC2 loadings show negative bands at 4648, 4740, 5116, 5296, 5720, 5896, $6896 \mathrm{~cm}^{-1}$ and positive ones at 5204,5824, $6996 \mathrm{~cm}^{-1}$. The negative signals are shifts of bands from $4632,4756,5140,5312,5720,5880,6908 \mathrm{~cm}^{-1}$ which are assigned to $\mathrm{CH}$ and $\mathrm{C}=\mathrm{O}$ groups in extractives, hemicelluloses and lignin, as well as weakly hydrogen-bonded $\mathrm{OH}$ groups in extractives and amorphous carbohydrates [7,23,37]. The positive signals in PC2 loadings represent shifts of bands from 5216 and $5796 \mathrm{~cm}^{-1}$ which are assigned to 
$\mathrm{CH}$ groups in hemicelluloses and to weakly hydrogen-bonded $\mathrm{OH}$ groups in amorphous carbohydrates $[7,23,37]$.

Because the bands assigned to extractives overlap with those assigned to lignin or hemicelluloses, it is difficult to identify their exact contribution. However, the bands appearing in PC2 loadings are opposite to those which appear in PC1.

\subsection{Two-Dimensional Correlation Spectroscopy (2D-COS)}

2D-COS is a powerful tool used to observe differences appearing in wood during external perturbation. The method enhances spectral resolution and gives information that cannot be established through conventional or derivative spectra. It was performed to identify spectral sequences and better differentiate between the differences which appear after extraction in the structure of samples. Figure 3 present examples of the 2D-COS maps in the $4520-5350 \mathrm{~cm}^{-1}$ region.

Synchronous and asynchronous spectra present differences both for non-extracted and water-extracted samples, as well as when a certain level of RH is used during the treatment. Synchronous spectra of thermal treated samples at $0 \% \mathrm{RH}$ present fewer modifications, indicating only three auto-peaks at 5280, 5216 and $4890 \mathrm{~cm}^{-1}$ and a series of positive and negative cross-peaks related to them for the non-extracted samples (Figure 3a) and only two auto-peaks at 5288 and $5204 \mathrm{~cm}^{-1}$ in water-extracted samples (Figure $3 \mathrm{a}^{\prime}$ ). At the same time, the synchronous spectra of thermally treated samples at $91 \%$ RH present eight autopeaks at 5280, 5220,5180,5120,4920, 4728, 4664 and $4580 \mathrm{~cm}^{-1}$ for non-extracted samples (Figure 3i) and at 5292, 5228, 5176, 5120, 4996, 4928, 4832, $4664 \mathrm{~cm}^{-1}$ for water-extracted samples (Figure $3 i^{\prime}$ ) as well as a series of positive and negative cross-peaks related to them.

Figure 4 represents auto-correlation spectra extracted from the synchronous spectra and differences which appear in the intensities and positions of the maxima of the autopeaks can be observed. Each set of samples present different behaviours, indicating the occurrence of different reactions taking place in the wood structure during treatment, reactions which are strongly dependent on the content of water present in the environment. At the same time, differences in auto-correlation spectra of non-extracted and waterextracted samples are observed, differences which appear to be more obvious for samples treated at high relative humidity. These modifications are correlated with the modifications observed in second derivative spectra, as well as loading plots.

Combining both synchronous and asynchronous spectra and following Noda's rules [28,30] it was possible to identify the auto-peaks and cross-peaks, as well as the sequential order of band modification under hydro-thermal treatment, as follows:

120_0_n: $4570 \mathrm{~cm}^{-1}>4612 \mathrm{~cm}^{-1}>4650 \mathrm{~cm}^{-1}>4904 \mathrm{~cm}^{-1}>5280 \mathrm{~cm}^{-1}>5216 \mathrm{~cm}^{-1}$

120_0_e: $5116 \mathrm{~cm}^{-1}>5204 \mathrm{~cm}^{-1}>5288 \mathrm{~cm}^{-1}>4920 \mathrm{~cm}^{-1}>4724 \mathrm{~cm}^{-1}>4668 \mathrm{~cm}^{-1}$, $4628 \mathrm{~cm}^{-1}>4580 \mathrm{~cm}^{-1}$

120_35_n: $4570 \mathrm{~cm}^{-1}>4612 \mathrm{~cm}^{-1}>4650 \mathrm{~cm}^{-1}>4904 \mathrm{~cm}^{-1}>5280 \mathrm{~cm}^{-1}>5216 \mathrm{~cm}^{-1}$

120_35_e: $5116 \mathrm{~cm}^{-1}>5204 \mathrm{~cm}^{-1}>5288 \mathrm{~cm}^{-1}>4920 \mathrm{~cm}^{-1}>4724 \mathrm{~cm}^{-1}>4668 \mathrm{~cm}^{-1}$, $4628 \mathrm{~cm}^{-1}>4580 \mathrm{~cm}^{-1}$ $\mathrm{cm}^{-1}$

120_60_n: $4570 \mathrm{~cm}^{-1}>4650 \mathrm{~cm}^{-1}>4724 \mathrm{~cm}^{-1}>4915 \mathrm{~cm}^{-1}>5120,5216 \mathrm{~cm}^{-1}>5280$

120_60_e: $5120 \mathrm{~cm}^{-1}>5210 \mathrm{~cm}^{-1}>5280 \mathrm{~cm}^{-1}>4570,4990 \mathrm{~cm}^{-1}>4910 \mathrm{~cm}^{-1}>4665$ $\mathrm{cm}^{-1}>4740 \mathrm{~cm}^{-1}$

120_80_n: $4724 \mathrm{~cm}^{-1}>5225,5128 \mathrm{~cm}^{-1}>4916 \mathrm{~cm}^{-1}>4652 \mathrm{~cm}^{-1}>4590 \mathrm{~cm}^{-1}>5172$ $\mathrm{cm}^{-1}>5280 \mathrm{~cm}^{-1}$

120_80_e: $5288 \mathrm{~cm}^{-1}>5130,5188 \mathrm{~cm}^{-1}>4921 \mathrm{~cm}^{-1}>4995 \mathrm{~cm}^{-1}>4740 \mathrm{~cm}^{-1}>4570$ $\mathrm{cm}^{-1}>5240 \mathrm{~cm}^{-1}>4650 \mathrm{~cm}^{-1}$

120_91_n: $4728 \mathrm{~cm}^{-1}>5120 \mathrm{~cm}^{-1}>4920 \mathrm{~cm}^{-1}>4590 \mathrm{~cm}^{-1}>4664 \mathrm{~cm}^{-1}>5230 \mathrm{~cm}^{-1}$ $>5180 \mathrm{~cm}^{-1}>5284 \mathrm{~cm}^{-1}$

120_91_e: $5292 \mathrm{~cm}^{-1}>5228 \mathrm{~cm}^{-1}>5120 \mathrm{~cm}^{-1}>5176 \mathrm{~cm}^{-1}>4750 \mathrm{~cm}^{-1}, 4832 \mathrm{~cm}^{-1}$, $4996 \mathrm{~cm}^{-1}>4928 \mathrm{~cm}^{-1}>4664 \mathrm{~cm}^{-1}$ 


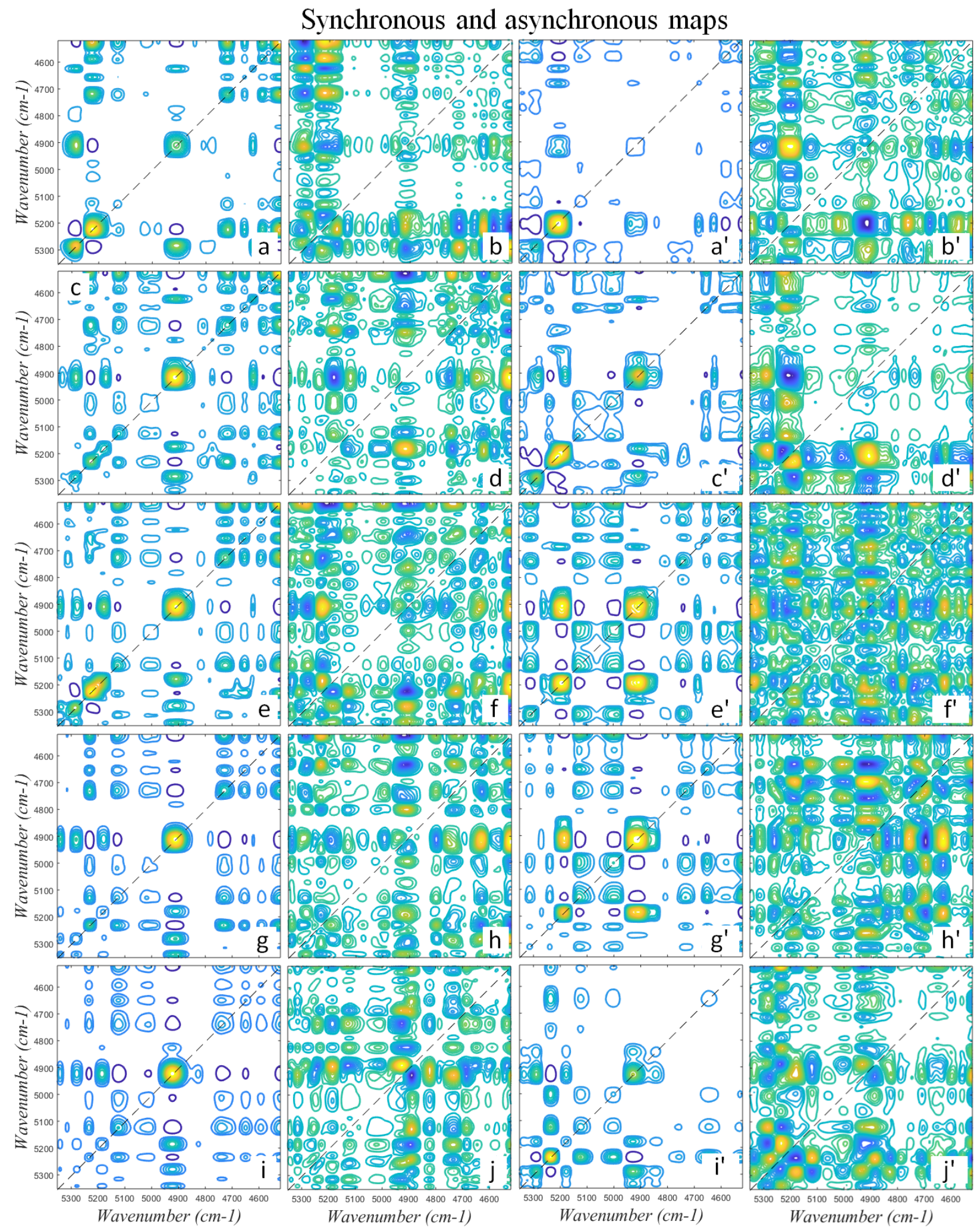

Figure 3. Synchronous $(\mathbf{a}, \mathbf{c}, \mathbf{e}, \mathbf{g}, \mathbf{i})$ and asynchronous $(\mathbf{b}, \mathbf{d}, \mathbf{f}, \mathbf{h}, \mathbf{j})$ maps of the spectra of the non-extracted (a-j) and waterextracted $\left(\mathbf{a}^{\prime}-\mathbf{j}^{\prime}\right)$ reference $(\mathbf{a}, \mathbf{b})$ and hydrothermal treated wood samples at $35(\mathbf{c}, \mathbf{d}), 60(\mathbf{e}, \mathbf{f}), 80(\mathbf{g}, \mathbf{h})$ and $91(\mathbf{i}, \mathbf{j}) \% R H$. 


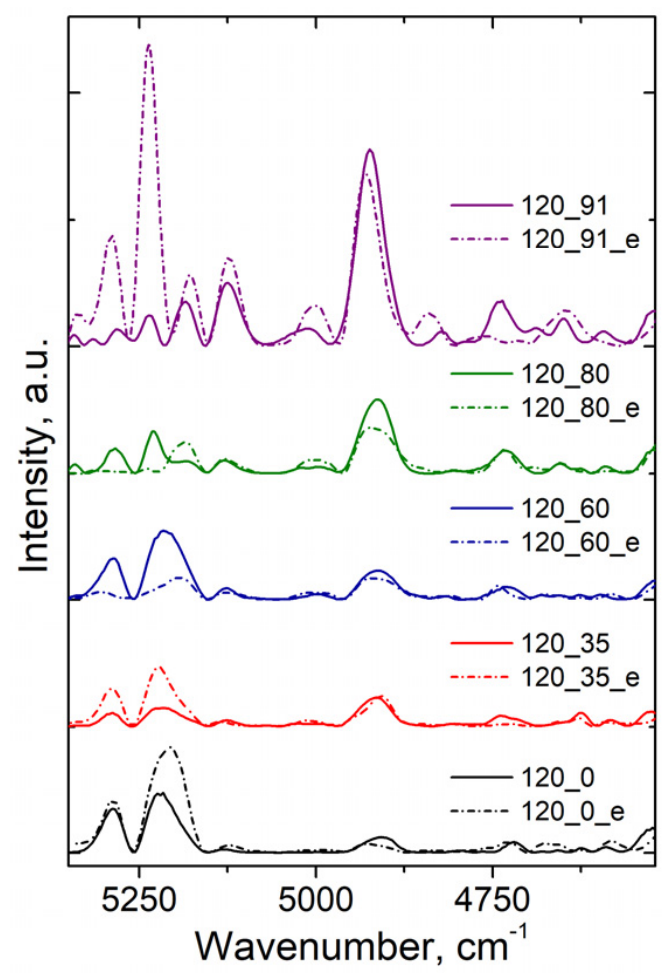

Figure 4. Autocorrelation spectra extracted from the synchronous spectra for the $4520-5350 \mathrm{~cm}^{-1}$ region $\left(\mathrm{T}=120^{\circ} \mathrm{C}, \mathrm{RH}=0,35,60,80,91 \%\right.$, e-extracted $)$.

In non-extracted samples the bands related to $\mathrm{O}-\mathrm{H}, \mathrm{C}-\mathrm{H}$ groups in hemicelluloses are modified first, followed by the $\mathrm{C}=\mathrm{O}$ and $\mathrm{C}-\mathrm{H}$ groups in extractives and lignin, and $\mathrm{O}-\mathrm{H}$ groups involved in stronger hydrogen bonds. In water-extracted samples it is observed that the first modifications occur for the bands assigned to $\mathrm{O}-\mathrm{H}$ groups involved in stronger hydrogen bonds followed by $\mathrm{C}=\mathrm{O}$ and $\mathrm{C}-\mathrm{H}$ groups from extractives and lignin.

It is known that a series of processes takes place when wood is exposed to thermal or hydro-thermal treatment. During the thermal treatment in dry conditions, wood (especially hemicelluloses, extractives and to some extent lignin) undergoes a series of reactions, such as: oxidation, dehydration and/or decarboxylation combined with mass and heat transfer, as well as molecular rearrangements and conformational changes. In wet conditions (depending on the amount of water present in the medium) - hydro-thermal treatment-the degradation reactions occur more quickly and hydrolysis reactions occur prior to oxidation (due to water which act as a catalyst) leading to the formation of saturated and unsaturated structures and the crystallization of wood cellulose might be affected $[7,21,41]$. The degradation of wood components is reached mostly by means of hydronium catalysed reactions, at a first stage, when these ions are generated from the water molecule autohydrolysis, followed by generation of the acetic acid (the hydrolysis of the acetyl groups from the wood structure). Further ionization provides most of the catalytic species involved in the degradation process [42]. Dehydration reactions cause the decomposition of hydrolysed sugars and deacetylation is caused by the cleavage of acetyl groups linked as ester groups to hemicelluloses. Moreover, it has been mentioned in the literature [12] that the presence of water molecules in the medium, during the thermal process can prevent oxidative processes, "favouring" hydrolysis. All depends on the wood structure-the susceptibility to hydro thermolysis of a specific type of wood depends on its ability to generate acetic acid in the reaction media [43] as well as the applied temperature, treatment time, and moisture content. 


\section{Conclusions}

Sitka spruce wood samples were treated at $120^{\circ} \mathrm{C}$ using different values $(0,35,60$, 80 and $91 \%$ ) of relative humidity during treatment. After treatment, the modifications were analyzed by NIR spectroscopy coupled with PCA and 2D-COS. Modification in chemical structure of thermally and hydro-thermally treated wood were observed, with higher variation occurring with an increase in time and RH. Hemicelluloses were the most sensitive to the applied treatment, but also lignin and cellulose were affected to some extent. Thermal degradation of hemicelluloses starts with the release of acetic acid in the medium, which induces further the acid catalysed reactions. Modification in the cellulose structure by affecting the semi-crystalline and crystalline regions and demethoxylation and condensation reactions in lignin structure were also observed. All these modifications result in the release of low molecular weight compounds which are released during treatment, and were extracted in water or remained trapped in the wood.

Further PCA was able to separate the modifications occurring in wood structure according to relative humidity variations and time (via PC1) and non-extracted and extracted wood (via PC2). 2D-COS gave information about the sequential order of modifications taking place in the wood structure after the hydro-thermal treatment and water extraction.

Author Contributions: Conceptualization, C.-M.P. and E.O.; methodology, C.-M.P. and T.G.; software, C.-M.P.; investigation, C.-M.P., N.Z., K.E., M.M.-U.; resources, E.O.; writing-original draft preparation, C.-M.P.; writing-review and editing, C.-M.P., E.O., T.G., N.Z., K.E., M.M.-U.; funding acquisition, E.O. All authors have read and agreed to the published version of the manuscript.

Funding: This research was funded by JSPS (FY2018-L18536) International Research Fellowship Program.

Data Availability Statement: Data available on request.

Acknowledgments: This work has been performed under the JSPS (FY2018) International Research Fellowship Program. Carmen-Mihaela Popescu acknowledges the financial support as a JSPS International Research Fellow-FY2018-L18536.

Conflicts of Interest: The authors declare no conflict of interest.

\section{References}

1. Chang, T.C.; Chang, H.T.; Wu, C.L.; Lin, H.Y.; Chang, S.T. Stabilizing effect of extractives on the photo-oxidation of Acacia confusa wood. Polym. Degrad. Stabil. 2010, 95, 1518-1522. [CrossRef]

2. Mazela, B.; Popescu, C.-M. Solid Wood, in Ch2: Wood as bio-based building materials. In Performance of Bio-Based Building Materials; Jones, D., Brischke, C., Eds.; Wood head Publishing Elsevier: Sawston, UK, 2017; pp. 22-39.

3. Assor, C.; Placet, V.; Chabbert, B.; Habrant, A.; Lapierre, C.; Pollet, B.; Perre, P. Concomitant changes in viscoelastic properties and amorphous polymers during the hydrothermal treatment of hardwood and softwood. J. Agric. Food Chem. 2009, 57, 6830-6837. [CrossRef]

4. Fackler, K.; Schwanninger, M. Accessibility of hydroxyl groups of brown-rot degraded spruce wood to heavy water. J. Near Infrared Spectrosc. 2011, 19, 359-368. [CrossRef]

5. Lekounougou, S.; Kocaefe, D. Comparative study on the durability of heat-treated White Birch (Betula papyrifera) subjected to the attack of brown and white rot fungi. Wood Mater. Sci. Eng. 2012, 7, 101-106. [CrossRef]

6. Popescu, C.-M.; Gradinariu, P.; Popescu, M.-C. Structural analysis of lime wood biodegraded by white rot fungi through infrared and two dimensional correlation spectroscopy techniques. J. Mol. Struct. 2016, 1124, 78-84. [CrossRef]

7. Popescu, C.-M.; Navi, P.; Placencia Peña, M.I.; Popescu, M.-C. Evaluation of the structural changes occurring in wood during hydro-thermal and thermal treatment using NIR spectroscopy and principal component analysis. Spectrochim. Acta A 2018, 191, 405-412. [CrossRef]

8. Zeniya, N.; Obataya, E.; Endo-Ujiie, K.; Matsuo-Ueda, M. Application of time-temperature-humidity superposition to the mass loss of wood through hygrothermally accelerated ageing at $95-140{ }^{\circ} \mathrm{C}$ and different relative humidity levels. SN Appl. Sci. 2019, 1, 3. [CrossRef]

9. Zeniya, N.; Obataya, E.; Endo-Ujiie, K.; Matsuo-Ueda, M. Changes in vibrational properties and colour of spruce wood by hygrothermally accelerated ageing at $95-140{ }^{\circ} \mathrm{C}$ and different relative humidity levels. SN Appl. Sci. 2019, 1, 7. [CrossRef]

10. Popescu, C.-M.; Popescu, M.-C.; Vasile, C. Structural analysis of photodegraded lime wood by means of FT-IR and 2D IR correlation spectroscopy. Int. J. Biol. Macromol. 2011, 48, 667-675. [CrossRef] 
11. Tolvaj, L.; Popescu, C.-M.; Molnar, Z.; Preklet, E. Dependence of the Air Relative Humidity and Temperature on the Photodegradation Processes of Beech and Spruce Wood Species. BioRes 2016, 11, 296-305.

12. Hill, C.A.S. Wood Modification: Chemical, Thermal and Other Processes; Wiley: Chichester, UK, 2006.

13. Sandberg, D.; Haller, P.; Navi, P. Thermo-hydro and thermo-hydro-mechanical wood processing: An opportunity for future environmentally friendly wood products. Wood Mater. Sci. Eng. 2013, 8, 64-88. [CrossRef]

14. Esteves, B.M.; Pereira, H.M. Wood modification by heat treatment: A review. BioRes 2009, 4, 370-404. [CrossRef]

15. Candelier, K.; Chaouch, M.; Dumarcay, S.; Pétrissans, A.; Pétrissans, M.; Gérardin, P. Utilization of thermodesorption coupled to GC-MS to study stability of different wood species to thermodegradation. J. Anal. Appl. Pyrol. 2011, 92, 376-383. [CrossRef]

16. Matsuo, M.; Yokoyama, M.; Umemura, K.; Sugiyama, J.; Kawai, S.; Gril, J.; Kubodera, S.; Mitsutani, T.; Ozaki, H.; Sakamoto, M.; et al. Ageing of wood: Analysis of color changes during natural ageing and heat treatment. Holzforschung 2011, 65, 361-368. [CrossRef]

17. Endo, K.; Obataya, E.; Zeniya, N.; Matsuo, M. Effects of heating humidity on the physical properties of hydrothermal treated spruce wood. Wood Sci. Technol. 2016, 50, 1161-1179. [CrossRef]

18. Bekhta, P.; Niemz, P. Effect of high temperature on the change in color, dimensional stability and mechanical properties of spruce wood. Holzforschung 2003, 57, 539-546. [CrossRef]

19. Borrega, M.; Kärenlampi, P.P. Mechanical behavior of heat-treated spruce (Picea abies) wood at constant moisture content and ambient humidity. Holz. Roh. Werkst. 2008, 66, 63-69. [CrossRef]

20. Borrega, M.; Kärenlampi, P.P. Hygroscopicity of heat-treated Norway spruce (Picea abies) wood. Eur. J. Wood Prod. 2010, 68, 233-235. [CrossRef]

21. Popescu, C.-M.; Popescu, M.-C. A near infrared spectroscopic study of the structural modifications of lime (Tilia cordata Mill.) wood during hydro-thermal treatment. Spectrochim. Acta A 2013, 115, 227-233. [CrossRef] [PubMed]

22. Zeniya, N.; Endo-Ujiie, K.; Obataya, E.; Nakagawa-Izumi, A.; Matsuo-Ueda, M. Effects of water-soluble extractives on the vibrational properties and color of hygrothermally treated spruce wood. Wood Sci. Technol. 2019, 53, 151-164. [CrossRef]

23. Schwanninger, M.; Rodrigues, J.C.; Fackler, K. A review of band assignments in near infrared spectra of wood and wood components. J. Near Infrared Spectrosc. 2011, 19, 287-308. [CrossRef]

24. Meder, R.; Thumm, A.; Bier, H. Venner stiffness predicted by NIR spectroscopy calibrated using mini-LVL test panels. Holz als Roh- und Werkstoff 2002, 60, 159-164. [CrossRef]

25. Schwanninger, M.; Hinterstoisser, B.; Gierlinger, N.; Wimmer, R.; Hnager, J. Application of Fourier Transform Near Infrared Spectroscopy (FT-NIR) to thermally modified wood. Holz als Roh- und Werkstoff 2004, 62, 483-485. [CrossRef]

26. Via, B.K.; Zhou, C.; Acquah, G.; Jiang, W.; Eckhardt, L. Near Infrared Spectroscopy Calibration for Wood Chemistry: Which Chemometric Technique Is Best for Prediction and Interpretation? Sensors 2014, 14, 13532-13547. [CrossRef]

27. dos Santos Grasel, F.; Flôres Ferrão, M.; Wolf, C.R. Development of methodology for identification the nature of the polyphenolic extracts by FTIR associated with multivariate analysis. Spectrochim. Acta A 2016, 153, 94-101. [CrossRef]

28. Noda, I. Generalized two-dimensional correlation method applied to infrared, Raman, and other types of spectroscopy. Appl. Spectrosc. 1993, 47, 1329-1336. [CrossRef]

29. Czarnecki, M.A. Interpretation of Two-Dimensional Correlation Spectra: Science or Art? Appl. Spectrosc. 1998, 52, 1583-1590. [CrossRef]

30. Noda., I.; Ozaki., Y. Two Dimensional Correlation Spectroscopy: Applications in Vibrational and Optical Spectroscopy; John Wiley \& Sons Ltd.: Chichester, UK, 2004.

31. Popescu, C.-M.; Popescu, M.-C.; Singurel, G.; Vasile, C.; Argyropoulos, D.S.; Willför, S. Spectral characterization of Eucalyptus wood. Appl. Spectrosc. 2007, 61, 1168-1177. [CrossRef]

32. Wanga, C.; Xianga, B.; Zhanga, W. Application of two-dimensional near-infrared (2D-NIR) correlation spectroscopy to the discrimination of three species of Dendrobium. J. Chemometrics. 2009, 23, 463-470. [CrossRef]

33. Workman, J., Jr.; Weyer, L. Practical Guide to Interpretive Near-Infrared Spectroscopy; CRC Press: Boca Raton, FL, USA, 2008.

34. Basch, A.; Wasserman, T.; Lewin, M. Near-Infrared Spectrum of cellulose: A new method for obtaining crystallinity ratios. J. Polym. Sci. Polym. Chem. 1974, 12, 1143-1156. [CrossRef]

35. Vasile, C.; Popescu, M.-C.; Stoleriu, A.; Gosselink, R. Thermal characterization of lignins. In New Trends in Natural and Synthetic Polymer Science; Vasile, C., Zaikov, G.E., Eds.; Nova Science Publishers Inc.: New York, NY, USA, 2006; pp. 135-163.

36. Hatakeyama, H. Thermal Analysis. In Methods in Lignin Chemistry; Lin, S.Y., Dence, C.W., Eds.; Springer: Berlin, Germany, 1992; p. 200.

37. Inagaki, T.; Matsuo, M.; Tsuchikawa, S. NIR spectral-kinetic analysis for thermally degraded Sugi (Cryptomeria japonica) wood. Appl. Phys. A 2016, 122, 208. [CrossRef]

38. Watanabe, A.; Morita, S.; Ozaki, Y. Temperature dependent structural changes in hydrogen bonds in microcrystalline cellulose studied by infrared and near-infrared spectroscopy with perturbation-correlation moving-window two-dimensional correlation analysis. Appl. Spectrosc. 2006, 60, 611-618. [CrossRef] [PubMed]

39. Mitsui, K.; Inagaki, T.; Tsuchikawa, S. Monitoring of hydroxyl groups in wood during heat treatment using NIR spectroscopy. Biomacromol 2008, 9, 286-288. [CrossRef]

40. Bächle, H.; Zimmer, B.; Windeisen, E.; Wegener, G. Evaluation of thermally modified beech and spruce wood and their properties by FT-NIR spectroscopy. Wood Sci. Technol. 2010, 44, 421-433. [CrossRef] 
41. Akgul, M.; Gumuskaya, E.; Korkut, S. Crystalline structure of heat-treated Scots pine [Pinus sylvestris L.] and Uludağ fir [Abies nordmanniana (Stev.) subsp. bornmuelleriana (Mattf.)] wood. Wood Sci. Technol. 2007, 41, 281-289. [CrossRef]

42. Conner, A.H. Kinetic modeling of hardwood prehydrolysis. Part I: Xylan removal by water prehydrolysis. Wood Fiber. Sci. 1984, $16,268-277$.

43. Garrote, G.; Dominguez, H.; Parajó, J.C. Study of the deacetylation of hemicelluloses during the hydrothermal processing of Eucalyptus wood. Holz als Roh- und Werkstoff 2001, 59, 53-59. [CrossRef] 